Check for updates

Cite this: RSC Adv., 2018, 8, 25057

Received 24th May 2018

Accepted 5th July 2018

DOI: 10.1039/c8ra04436h

rsc.li/rsc-advances

\section{Confining the polymerization degree of graphitic carbon nitride in porous zeolite- $Y$ and its luminescence}

\begin{abstract}
Wei Wan, Jia-Yi Sun, Shi Ye (DD* and Qin-yuan Zhang (DD *
Graphitic carbon nitride $\left(\mathrm{g}-\mathrm{C}_{3} \mathrm{~N}_{4}\right)$ has aroused broad interest in the field of photocatalysis and luminescence as a kind of metal-free semiconductor with a suitable band gap of $\sim 2.7 \mathrm{eV}$. The properties largely depend on the polymerization degree of $\mathrm{g}-\mathrm{C}_{3} \mathrm{~N}_{4}$. This research exploits the nanocages of zeolite- $\mathrm{Y}$ to confine the polymerization of the melamine monomer to form $\mathrm{g}-\mathrm{C}_{3} \mathrm{~N}_{4}$. The composites are achieved via a facile two-step method, i.e., melamine- $\mathrm{Na}^{+}$ion exchange reaction in the cage of the zeolite and subsequent calcination. BET measurement and transmission electron microscopy (TEM) confirm that the $g-C_{3} N_{4}$ is encapsulated in zeolite- $Y$, and the polymerization degree can be controlled by the melamine contents exchanged with $\mathrm{Na}^{+}$in the cages of zeolite-Y. Photoluminescence and vibration spectroscopy also show the features of $\mathrm{g}-\mathrm{C}_{3} \mathrm{~N}_{4}$ with different polymerization degrees in the zeolite-Y composites. This research gives a perspective of fabricating subnanoscale $\mathrm{g}-\mathrm{C}_{3} \mathrm{~N}_{4}$ in porous zeolite, which may find potential applications in photocatalysis and optoelectronics.
\end{abstract}

\section{Introduction}

As a kind of carbon nitride allotrope, graphitic carbon nitride ( $\mathrm{g}$ $\mathrm{C}_{3} \mathrm{~N}_{4}$ ) is composed of heptazine tectonic units and pendant amino groups. Benefitting from its special layer structure and electronic structure, $\mathrm{g}-\mathrm{C}_{3} \mathrm{~N}_{4}$ has become a novel organic and metal-free semiconductor with outstanding heat endurance and chemical resistance in the ambient environment. ${ }^{1}$ Owing to the suitable band gap of $2.7 \mathrm{eV}, \mathrm{g}-\mathrm{C}_{3} \mathrm{~N}_{4}$ also exhibits excellent photocatalytic properties under irradiation with visible light, including photo-degradation, photocatalytic NO removal and photocatalytic water splitting. ${ }^{2-18}$ Various synthetic methods and techniques, such as solvothermal synthesis, physical vapor deposition, chemical vapor deposition, thermal nitridation, etc., have been employed to produce g- $\mathrm{C}_{3} \mathrm{~N}_{4}$. Additionally, a moderate approach ensuring the thermal condensation of simple organic monomers like melamine was reported to synthesize g- $\mathrm{C}_{3} \mathrm{~N}_{4}$ as a low cost and simple synthetic method. ${ }^{19}$ Distinct photoluminescence (PL) properties can be acquired for the $\mathrm{g}_{-} \mathrm{C}_{3} \mathrm{~N}_{4}$ with varied polymerization degrees, which was achieved via condensation of melamine at different synthetic temperature. ${ }^{19,20}$ With the ongoing condensation of melamine monomers, melon is the first formed polymeric $\mathrm{C}_{3} \mathrm{~N}_{4}$ structure as an important intermediate precursor. Further reaction results in more polymerized and less defective g- $\mathrm{C}_{3} \mathrm{~N}_{4}{ }^{21,22}$ Thus,

State Key Laboratory of Luminescent Materials and Devices, Guangdong Provincial Key Laboratory of Fiber Laser Materials and Applied Techniques, South China University of Technology, Guangzhou 510641, China.E-mail: msyes@scut.edu.cn; qyzhang@scut. edu.cn controlling the condensation of melamine is of significance. Differing from changing the synthetic temperature, we report on a new method to control the polymerization of $\mathrm{g}-\mathrm{C}_{3} \mathrm{~N}_{4}$ by utilizing the confining effect of zeolite-Y's pores, which has not yet been reported to our best knowledge.

Zeolite-Y is builded up by $\left[\mathrm{AlO}_{4}\right]^{5-}$ and $\left[\mathrm{SiO}_{4}\right]^{4-}$ tetrahedra constituting an open 3D framework structure with cages and channels, which could accommodate particles smaller than $1.5 \mathrm{~nm} .{ }^{23-26}$ It also can be viewed as silica structure with partial $\left[\mathrm{SiO}_{4}\right]^{4-}$ units substituted by $\left[\mathrm{AlO}_{4}\right]^{5-}$, resulting in a negative charge of the structure stabilized by positive cations in the cages and channels. ${ }^{27}$ Zeolite-Y has been regarded as an outstanding host to encapsulate quantum dots (QDs) luminescent center, for preventing the QDs from attack of moisture, etc. ${ }^{28-33}$ Many approaches, including ion exchange, vapor impregnation and solid state diffusion, can be employed to introduce luminescent centers into the cages of zeolite-Y. ${ }^{34}$ Accordingly, the cations in the cages of zeolite-Y are supposed to be exchanged by the cationic amine, which would further condense to produce g$\mathrm{C}_{3} \mathrm{~N}_{4}$. Thus, utilizing the cages of zeolite-Y could be a feasible way to confine the polymerization of $\mathrm{g}-\mathrm{C}_{3} \mathrm{~N}_{4}$, which may find potential applications in photocatalysis, lighting device and chemical sensing, etc.

In this research, we report on a facile synthesis of porous zeolite-Y and $\mathrm{g}_{-} \mathrm{C}_{3} \mathrm{~N}_{4}$ composites, aiming to confine the polymerization of $\mathrm{g}-\mathrm{C}_{3} \mathrm{~N}_{4}$ and tune the resulted luminescence. We successfully synthesized the zeolite- $\mathrm{Y}$ and $\mathrm{g}-\mathrm{C}_{3} \mathrm{~N}_{4}$ composites by two steps. Melamine is first dissolved in deionized water and introduced into the pores of zeolite-Y as precursor via an ionexchange reaction. Through the thermal condensation of 
melamine in the second step, we eventually synthesized the zeolite-Y and $\mathrm{g}-\mathrm{C}_{3} \mathrm{~N}_{4}$ composites.

\section{Experimental section}

Materials and chemicals: Melamine powders (Aladdin, 99\%) and $\mathrm{Na}^{+}$-zeolite-Y $\left(\mathrm{SiO}_{2} / \mathrm{Al}_{2} \mathrm{O}_{3}=5.1\right.$, Alfa Aesar).

The zeolite-Y and g- $\mathrm{C}_{3} \mathrm{~N}_{4}$ composites (simplified as $\mathrm{CN}_{r}-\mathrm{Y}, r$ refers to the initial mass of melamine dissolved in $50 \mathrm{~mL}$ deionized water), were generally synthesized by two steps. Typically, the melamine exchanged zeolite-Y was firstly prepared. Detailedly, the amount of $r \mathrm{~g}(r=1.2,1.4$ or 2.0) of melamine powders were stirred and dissolved in $50 \mathrm{~mL}$ deionized water in a water bath at $80^{\circ} \mathrm{C}$ for $0.5 \mathrm{~h}$. Then $1.0 \mathrm{~g}$ of zeolite$\mathrm{Y}$ was added in melamine solution and magnetically stirred in a water bath at $80^{\circ} \mathrm{C}$ for $48 \mathrm{~h}$. The melamine-ion was introduced into the pores of zeolite-Y via the ion-exchange reaction. The asprepared precursors were repeatedly centrifuged and then washed with deionized water (for twice), and finally dried in air at $80{ }^{\circ} \mathrm{C}$ for $12 \mathrm{~h}$. In a second step, the as-prepared precursors were calcined at $550{ }^{\circ} \mathrm{C}$ under $\mathrm{N}_{2}$ atmosphere for $3 \mathrm{~h}$. The $\mathrm{CN}_{r}-\mathrm{Y}$ products were used directly for further investigation.

Bulk $\mathrm{g}-\mathrm{C}_{3} \mathrm{~N}_{4}$ was synthesized by direct heating $2 \mathrm{~g}$ of melamine powders at $550{ }^{\circ} \mathrm{C}$ under $\mathrm{N}_{2}$ atmosphere for $3 \mathrm{~h}$.

$\mathrm{X}$-ray diffraction (XRD) patterns of the samples were measured on a Rigaku D/max-IIIA X-ray diffractometer using $\mathrm{Cu}$ $\mathrm{K}_{\alpha}$ radiation $(\lambda=1.5418 \AA)$. Scanning electron microscopy (SEM) images were obtained using an FEI Nova Nano SEM 430 field-emission scanning electron microscopy. The transmission electron microscopy (TEM) images and elemental mapping of resin-embedded sections of $\mathrm{CN}_{r}-\mathrm{Y}$ were recorded on a JEOL JEM-2100F transmission electron microscope. The specific surface area of the samples was checked by BET measurement (Quantachrome Autosorb-iQ). PL and excitation spectra were recorded on an Edinburgh Instruments FLS 920 spectrometer with a red-sensitive photomultiplier tube (R928). Fluorescence lifetimes were measured on a Hamamatsu Photonics C1136711. Raman scattering spectroscopy measurements were carried out with $785 \mathrm{~nm}$ excitation using a micro-Raman spectroscopy (HORIBA JOBIN YVON LabRAM Aramis). Fourier transform infrared (FTIR) spectroscopy was carried out on Thermo Fisher NICOLET IS 50.

\section{Results and discussion}

\subsection{Synthesis, structure and morphology}

Fig. 1 depicts the schematic synthetic procedure of $\mathrm{CN}_{r}-\mathrm{Y}$. Fig. 2a shows XRD patterns of the bulk $\mathrm{g}-\mathrm{C}_{3} \mathrm{~N}_{4}$, the raw zeolite-Y and $\mathrm{CN}_{r}-\mathrm{Y}(r=1.2,1.4,2.0)$, respectively. For the pattern of bulk $\mathrm{g}-\mathrm{C}_{3} \mathrm{~N}_{4}$ (orange), two major peaks at around $12.9^{\circ}$ and $27.6^{\circ}$ are assigned to the in-plane structure packing of aromatic systems of (100) plane and the interlayer stacking of conjugated aromatic systems of (002) plane, respectively, indicating that it is the typical graphite phase..$^{21,35-38}$ It can be seen that both the patterns of $\mathrm{CN}_{1.2}-\mathrm{Y}$ (red) and raw zeolite-Y (olive) are in good agreement with reference pattern (black bar), which suggests that the porous zeolite framework is maintained for $\mathrm{CN}_{1.2}-\mathrm{Y}$.
Differently, the $\mathrm{CN}_{r}-\mathrm{Y}(r=1.4$ and 2.0) are almost amorphous with only one declined diffraction peak at around $6.7^{\circ}$, which show slightly shift to higher diffraction angle compared to that of the raw zeolite-Y. It is the typical fingerprint of zeolite-Y with microporous structure, suggesting that the framework of the $\mathrm{CN}_{r}-\mathrm{Y}(r=1.4$ and 2.0$)$ do not totally collapse.

Fig. $2 \mathrm{~b}$ and $\mathrm{c}$ depict the SEM images of $\mathrm{CN}_{1.2}-\mathrm{Y}$ and raw zeolite-Y, respectively. Obviously, the particles of the $\mathrm{CN}_{1.2}-\mathrm{Y}$ are angular with similar morphology and smooth surfaces compared to that of the raw zeolite-Y, suggesting that the exchanged melamine may take reaction inside the pores of zeolite-Y during calcination..$^{27,28}$

Fig. 3a is the adsorption-desorption isotherms of some typical samples. The adsorption-desorption behavior of each sample exhibits the typical porous feature. The maximum adsorption capacity of the raw zeolite-Y is $215.83 \mathrm{~g} \mathrm{~cm}^{-3}$, while that of $\mathrm{CN}_{1.2}-\mathrm{Y}$ and $\mathrm{CN}_{1.4}-\mathrm{Y}$ are $179.48 \mathrm{~g} \mathrm{~cm}^{-3}$ and $74.73 \mathrm{~g} \mathrm{~cm}^{-3}$, respectively. The specific surface area of these samples in Fig. 3b shows analogous tendency, suggesting that the melamine derived products are indeed encapsulated in cages of zeolite-Y, and higher melamine contents result in more filled structure of the porous zeolites. ${ }^{27}$ Further evidences by elemental mapping will be given in Fig. 4.

Fig. $4 \mathrm{a}$ is a TEM image of resin-embedded section of $\mathrm{CN}_{1.2}-\mathrm{Y}$ sample and the respective compositional elemental mapping images are shown in Fig. 4(b-f). It is worth noting that the homogeneous distribution of nitrogen element in the particles (broken pieces of a zeolite grain), as seen in Fig. 4c, which is a direct evidence for the supposedly formed $\mathrm{C}_{3} \mathrm{~N}_{4}$ encapsulated in the pores of zeolite-Y. Although the carbon element seems to be everywhere owing to the resin package, more carbon contents are found in the particles than that in the resin. The aluminum element, silicon element and oxygen element distribution share the same shapes, which are the profiles of zeolite-Y pieces. ${ }^{23}$ Considering the negative charged framework of the zeolite and the feature of ion exchange reaction, there should be electrostatic interaction between the zeolite-Y and $\mathrm{g}$ $\mathrm{C}_{3} \mathrm{~N}_{4}$.

\subsection{Photoluminescence properties}

The normalized emission spectra of bulk $\mathrm{g}-\mathrm{C}_{3} \mathrm{~N}_{4}$ and all $\mathrm{CN}_{r}-\mathrm{Y}$ $(r=1.2,1.4,2.0)$ samples are shown in Fig. 5a. All the $\mathrm{CN}_{r}-\mathrm{Y}(r=$ $1.2,1.4,2.0)$ samples apparently show two emission peaks with similar profiles, and the dominant emission peak of bulk $\mathrm{g}$ $\mathrm{C}_{3} \mathrm{~N}_{4}$ locates at around $456 \mathrm{~nm}$ under the excitation of $320 \mathrm{~nm}$. The dominant emission peaks of the $\mathrm{CN}_{r}-\mathrm{Y}(r=1.2,1.4,2.0)$ are located at around 386,410 , and $407 \mathrm{~nm}$, respectively, which are analogous with the previous reports on the different polymerization of $\mathrm{g}-\mathrm{C}_{3} \mathrm{~N}_{4}$ synthesized at various temperature. ${ }^{19,20}$ It is the direct evidence for the existence of $\mathrm{g}-\mathrm{C}_{3} \mathrm{~N}_{4}$ in the composites. The emissions of the $\mathrm{CN}_{r}-\mathrm{Y}$ samples clearly show blue shift in contrast with bulk g- $\mathrm{C}_{3} \mathrm{~N}_{4}$. Detailedly, the emission of $\mathrm{CN}_{r}-\mathrm{Y}$ exhibits red shift in the sequence of $r=1.2,1.4,2.0$, which is owed to the different polymerization degrees of $\mathrm{g}-\mathrm{C}_{3} \mathrm{~N}_{4}$. This is ascribed to the encapsulation of $\mathrm{g}-\mathrm{C}_{3} \mathrm{~N}_{4}$ in the cages of zeolite-Y with diameter of subnanoscale, resulting in a quantum 


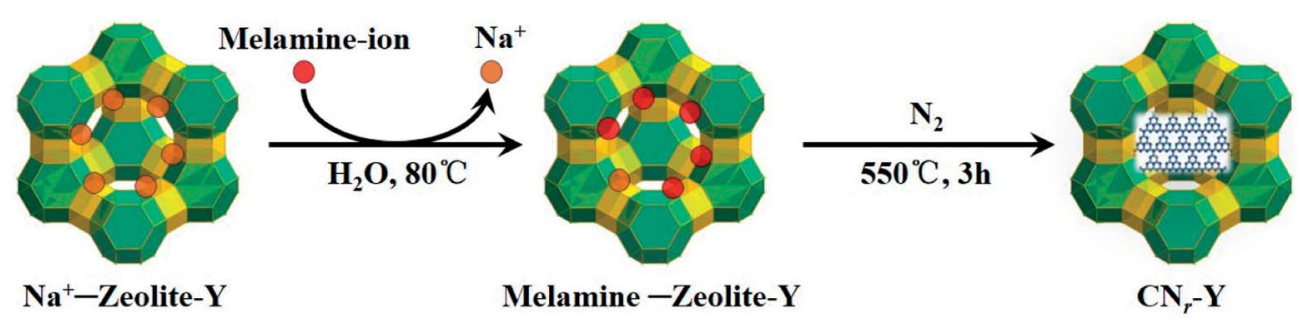

Fig. 1 Schematic illustration of the two-step synthesis of $\mathrm{CN}_{r}-\mathrm{Y}$, involving melamine-ion exchange followed by calcination.
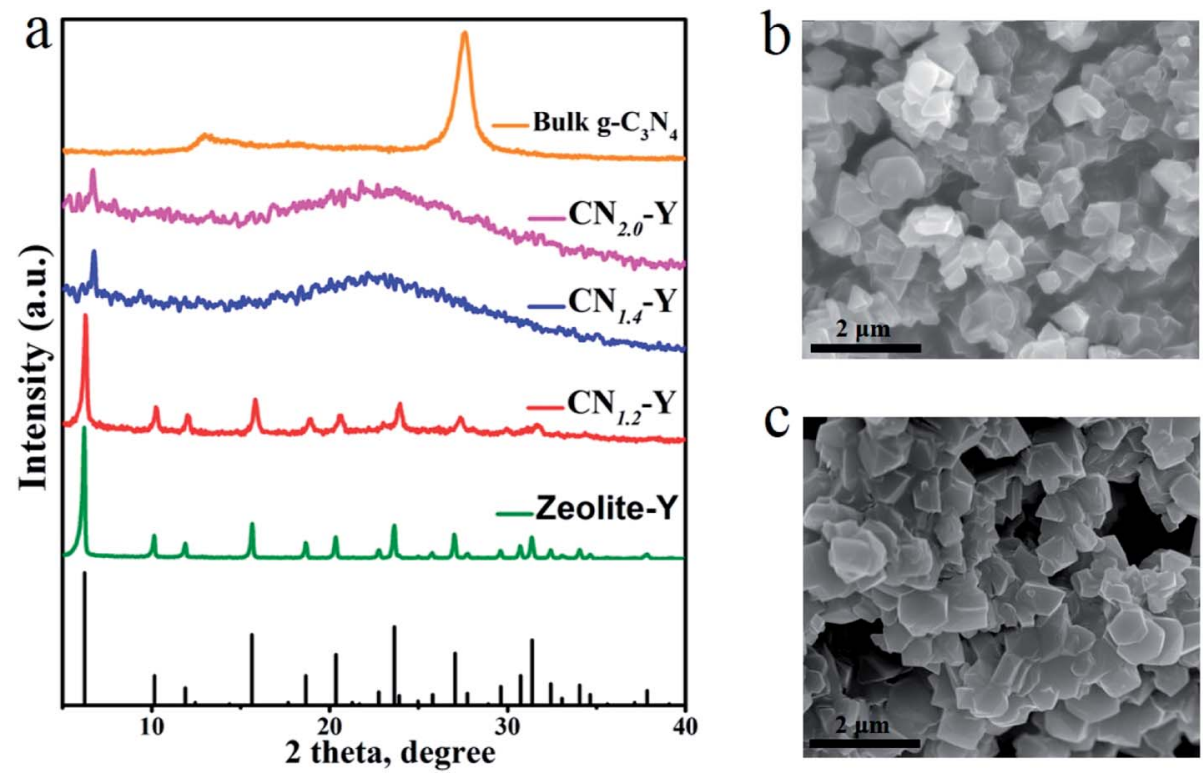

Fig. 2 (a) XRD patterns of the raw zeolite- $Y$ crystals (olive), the bulk $g-C_{3} N_{4}$ (orange), $C_{1.2}-Y$ (red), $C N_{1.4}-Y$ (blue) and $C N_{2.0}-Y$ (magenta), with the reference of JCPDS \#00-043-0168 (black bars). (b and c) SEM images of some typical samples: (b) the $\mathrm{CN}_{1.2}-\mathrm{Y}$ and (c) the raw zeolite-Y.

confinement effect on the electronic structure of the encapsulated $\mathrm{g}-\mathrm{C}_{3} \mathrm{~N}_{4} \cdot{ }^{24-26,39,40}$ Accordingly, all the excitation spectra in Fig. $5 \mathrm{~b}$ show similar trend.

With the help of Gaussian fitting of the PL peaks, we could obtain a clear understanding of these peaks. The fitted results of the $\mathrm{CN}_{1.4}-\mathrm{Y}$ sample are depicted in Fig. 6 a. It can be seen that the PL spectrum of $\mathrm{CN}_{1.4}-\mathrm{Y}$ sample has four emission peaks centered at $\mathrm{P}_{1}(396 \mathrm{~nm}), \mathrm{P}_{2}(427 \mathrm{~nm}), \mathrm{P}_{3}(467 \mathrm{~nm})$ and $\mathrm{P}_{4}$ (491 $\mathrm{nm})$, respectively. According to the previous research on $\mathrm{g}$ $\mathrm{C}_{3} \mathrm{~N}_{4},{ }^{19,41,42}$ the band-gap states of $\mathrm{g}-\mathrm{C}_{3} \mathrm{~N}_{4}$ are comprised of a sp ${ }^{2}$ $\mathrm{C}-\mathrm{N} \sigma$ band, $\mathrm{sp}^{3} \mathrm{C}-\mathrm{N} \pi$ band and the lone pair (LP) state of the bridge nitride atom (Fig. 6 b). The $\mathrm{P}_{1}, \mathrm{P}_{2}$, and $\mathrm{P}_{4}$ originate from
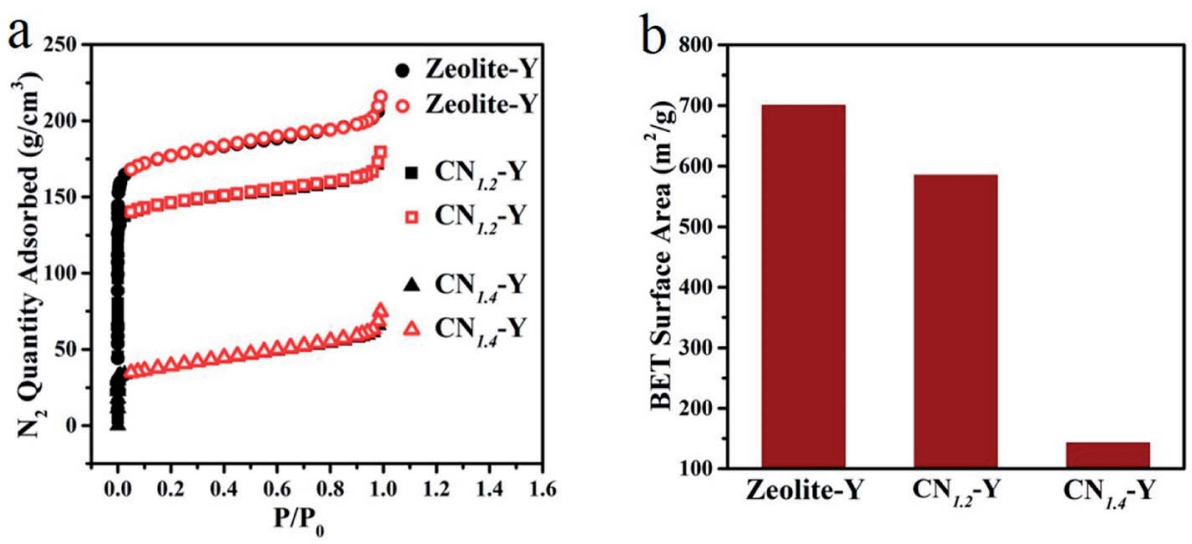

Fig. 3 ( $a$ and b) $N_{2}$ adsorption-desorption isotherms and specific surface area of the $\mathrm{CN}_{1.2}-\mathrm{Y}, \mathrm{CN}_{1.4}-\mathrm{Y}$ and the raw zeolite- $\mathrm{Y}$. 


\section{a}

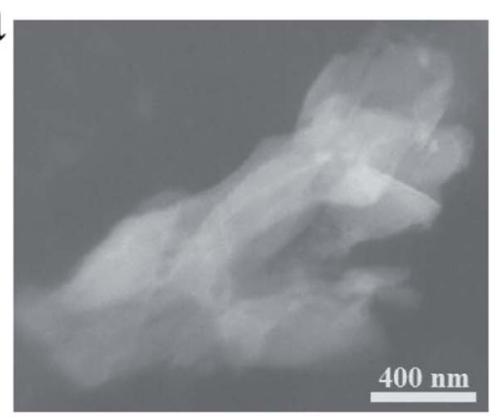

$\mathrm{b}$
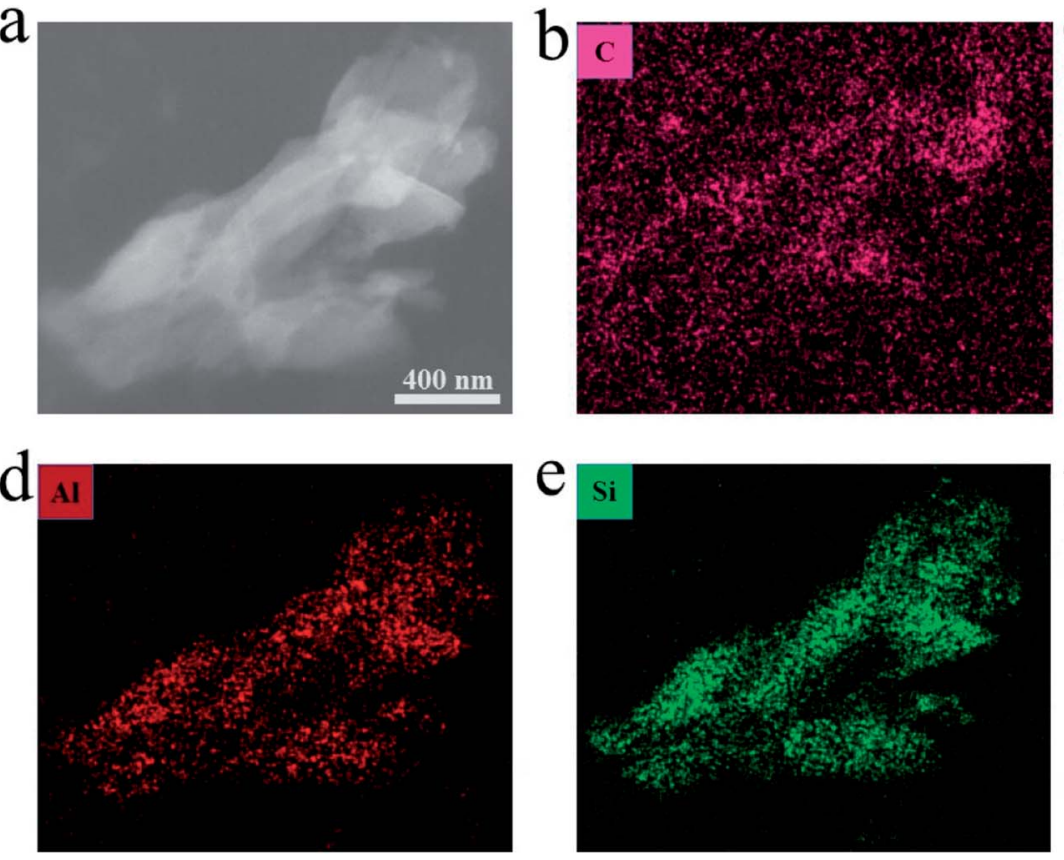

e

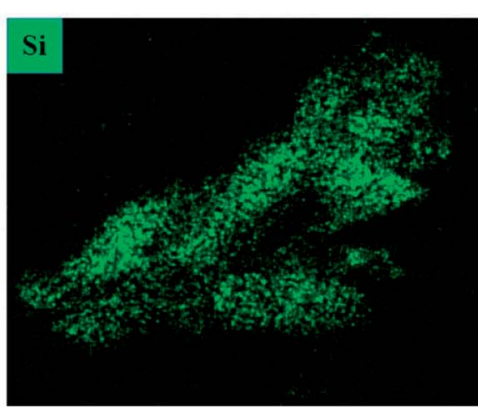

$\mathrm{C}$

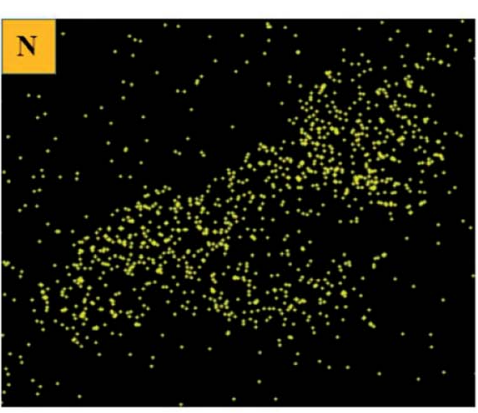

f

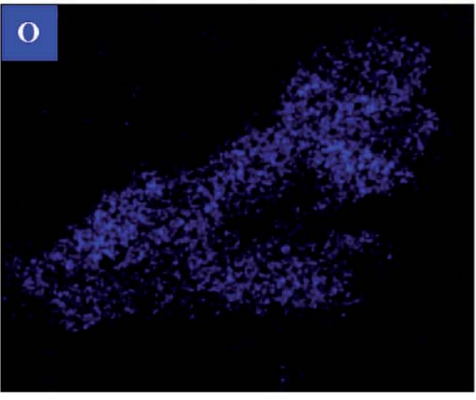

Fig. 4 (a) TEM image of the $\mathrm{CN}_{1.2}-\mathrm{Y}$. (b-f) The elemental mapping of $C, N, A l, \mathrm{Si}$ and $\mathrm{O}$ in the same particles.

the different transitions: $\sigma^{*}-\mathrm{LP}, \pi^{*}-\mathrm{LP}$ and $\pi^{*}-\pi$, respectively. The fitting peak positions of $\mathrm{CN}_{r}-\mathrm{Y}$ are depicted in Fig. 6c. The red shift of $\mathrm{P}_{1}$ and $\mathrm{P}_{2}$ reflects the extension of the encapsulated g- $\mathrm{C}_{3} \mathrm{~N}_{4}$ network, proving that the subnanocages of zeolite-Y can control the polymerization degree of $\mathrm{g}-\mathrm{C}_{3} \mathrm{~N}_{4}$. It is strongly evidenced by the emission blue shift of $\mathrm{CN}_{1.2}-\mathrm{Y}$ compared with that of $\mathrm{CN}_{r}-\mathrm{Y}(r=1.4$ or 2.0$) .{ }^{19,20}$ According to Füle et al., the size of the $\mathrm{sp}^{2}$ carbonic clusters should be within the range of 0.94$1.15 \mathrm{~nm}$ in order to enable the direction transition between the $\pi$ and $\pi^{*}$ bands. $^{38,41,43}$ The appearance of the $\pi^{*}-\pi$ transition bands of $\mathrm{CN}_{r}-\mathrm{Y}(r=1.2,1.4,2.0)$ samples, corresponding to the peak $\mathrm{P}_{4}$, directly proves that $\mathrm{g}-\mathrm{C}_{3} \mathrm{~N}_{4}$ is encapsulated in the pores of zeolite-Y with a diameter of subnanoscale. The peak position of $\mathrm{P}_{3}$ remains at around $467 \mathrm{~nm}$, which is probably due to the presence of $\mathrm{NH}_{2}$ on the edge and the defect of $\mathrm{C} \equiv \mathrm{N} .{ }^{38}$ It can be further proved in the FTIR spectroscopy.

The PL decay curves of the bulk g- $\mathrm{C}_{3} \mathrm{~N}_{4}$ and $\mathrm{CN}_{r}-\mathrm{Y}(r=1.2$, 1.4, 2.0) are presented in Fig. 6d, which are all monitored at their dominant emission peaks under the $320 \mathrm{~nm}$ excitation. All the samples show a fast decay component of 1.7-3.1 ns, which indicates that they share the same origin of $\sigma^{*}$-LP. While the samples other than $\mathrm{CN}_{1.2}-\mathrm{Y}$ exhibit a more complicated long decay, suggesting that a multiple process such as charge-carrier trapping may be involved for these higher polymerized samples. ${ }^{19,44}$

Low temperature PL measurements of the $\mathrm{CN}_{1.2}-\mathrm{Y}, \mathrm{CN}_{1.4}-\mathrm{Y}$ and bulk $\mathrm{g}-\mathrm{C}_{3} \mathrm{~N}_{4}$ were carried out and the results are given in Fig. 7a, b and c, respectively. All their emissions are gradually
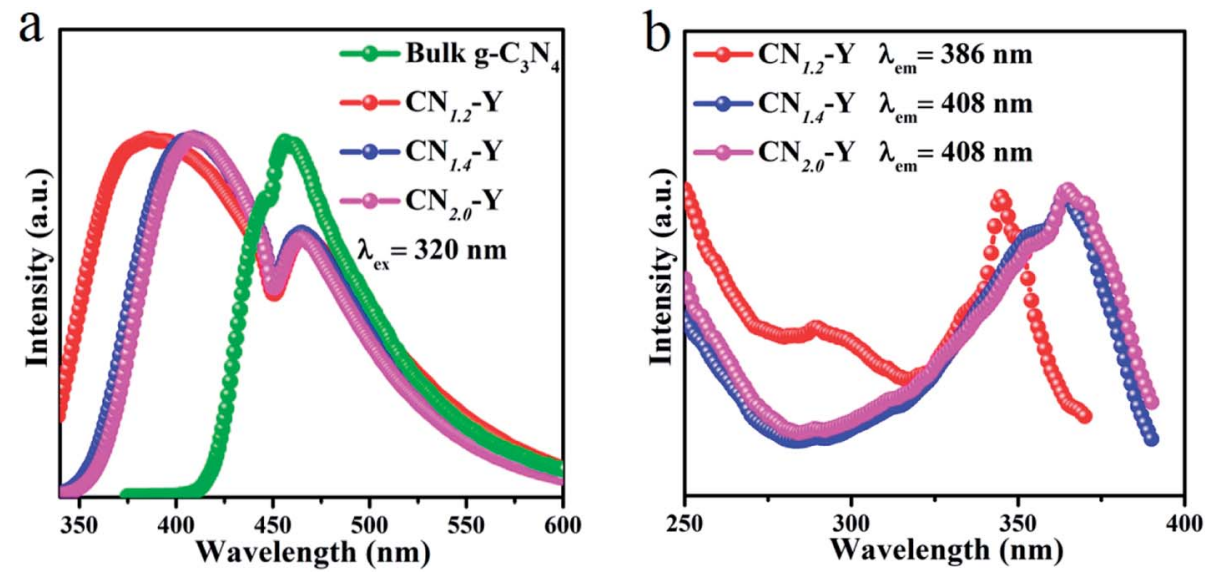

Fig. 5 (a) The normalized PL emission spectra of the $\mathrm{CN}_{r}-\mathrm{Y}(r=1.2,1.4,2.0)$ and bulk $g-\mathrm{C}_{3} \mathrm{~N}_{4}$. (b) The normalized excitation spectra of the $\mathrm{CN}_{r}-\mathrm{Y}$ $(r=1.2,1.4,2.0)$ 

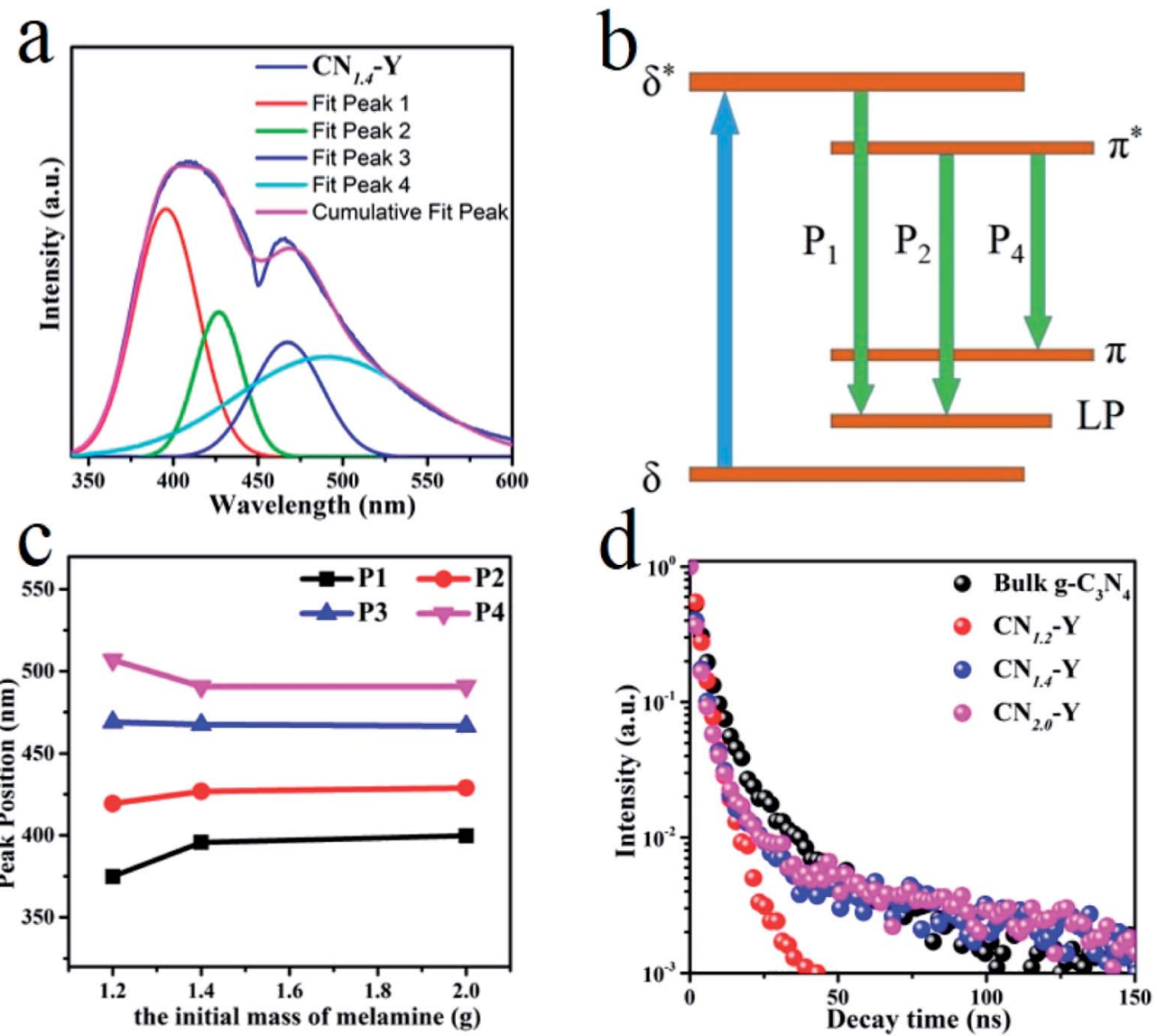

Fig. 6 (a) The Gaussian fitting of $P L$ emission spectra of the $C N_{1.4}-Y$ sample into $4 P L$ peaks $\left(P_{1}, P_{2}, P_{3}\right.$ and $P_{4}$, respectively). (b) The schematic diagram of the bandgap states of $\mathrm{g}-\mathrm{C}_{3} \mathrm{~N}_{4}$. (c) The peak position of $\mathrm{P}_{1}, \mathrm{P}_{2}, \mathrm{P}_{3}$ and $\mathrm{P}_{4}$ of the $\mathrm{CN}_{r}-\mathrm{Y}(r=1.2,1.4,2.0)$. (d) The decay curves of the $C \mathrm{~N}_{r}-$ $\mathrm{Y}(r=1.2,1.4,2.0)$ and bulk $\mathrm{g}-\mathrm{C}_{3} \mathrm{~N}_{4}$

enhanced with the decline of temperatures. While the peak locations and profiles remain unchanged for $\mathrm{CN}_{1.4}-\mathrm{Y}$ and bulk $\mathrm{g}^{-} \mathrm{C}_{3} \mathrm{~N}_{4}$ as the temperature decreases. Differing from this phenomenon, the edge at short wavelength shows red shift for $\mathrm{CN}_{1.2} \mathrm{Y}$ as the temperature decreases, which could ascribed to the lower polymerization degree of $\mathrm{g}-\mathrm{C}_{3} \mathrm{~N}_{4}$ for $\mathrm{CN}_{1.2}-\mathrm{Y}$ than that of $\mathrm{CN}_{1.4}-\mathrm{Y}$ and bulk g- $\mathrm{C}_{3} \mathrm{~N}_{4}$.

\subsection{Raman spectroscopy and FTIR spectroscopy}

To further identify the composition of the composites, Raman spectroscopy of the raw zeolite-Y, melamine, bulk g- $\mathrm{C}_{3} \mathrm{~N}_{4}$ and all $\mathrm{CN}_{r}-\mathrm{Y}(r=1.2,1.4,2.0)$ samples were recorded and the results are presented in Fig. 8a. Typical Raman peaks of bulk g- $\mathrm{C}_{3} \mathrm{~N}_{4}$ locate at around 707 and $1233 \mathrm{~cm}^{-1}$, which are induced by the heptazine ring breathing mode and stretching vibration modes of $\mathrm{C}=\mathrm{N}$ and $\mathrm{C}-\mathrm{N}$ hetero-cycles, respectively. These features
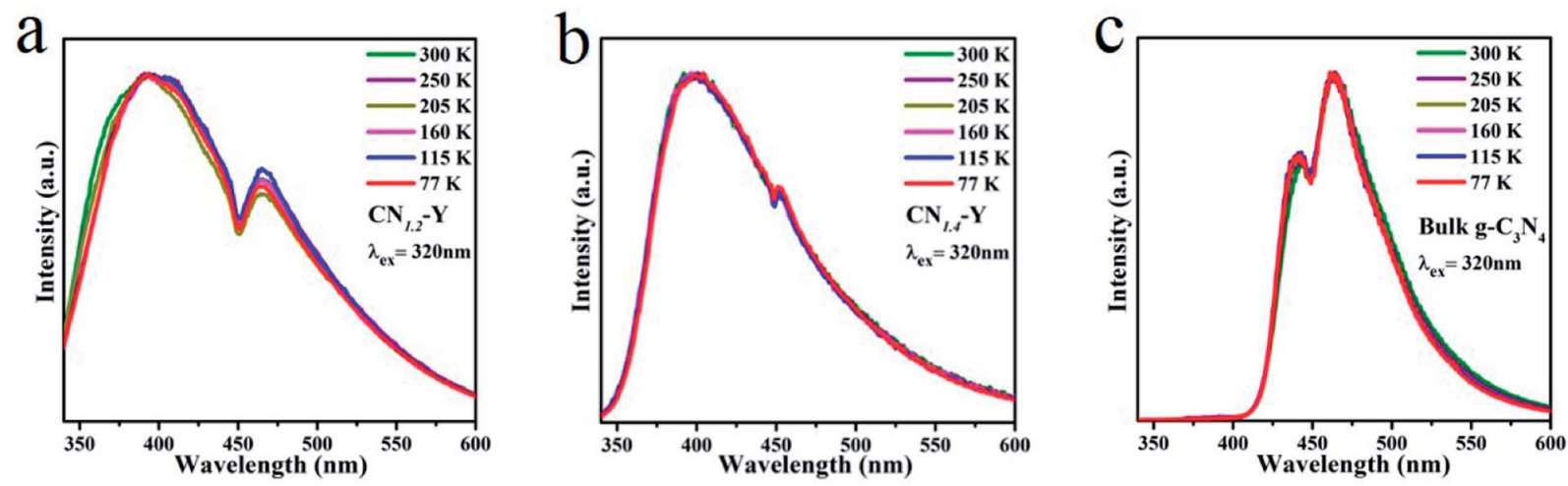

Fig. 7 (a-c) The normalized PL emission spectra of the $\mathrm{CN}_{1.2}-\mathrm{Y}, \mathrm{CN}_{1.4}-\mathrm{Y}$ and bulk $\mathrm{g}-\mathrm{C}_{3} \mathrm{~N}_{4}$ at various temperatures. 

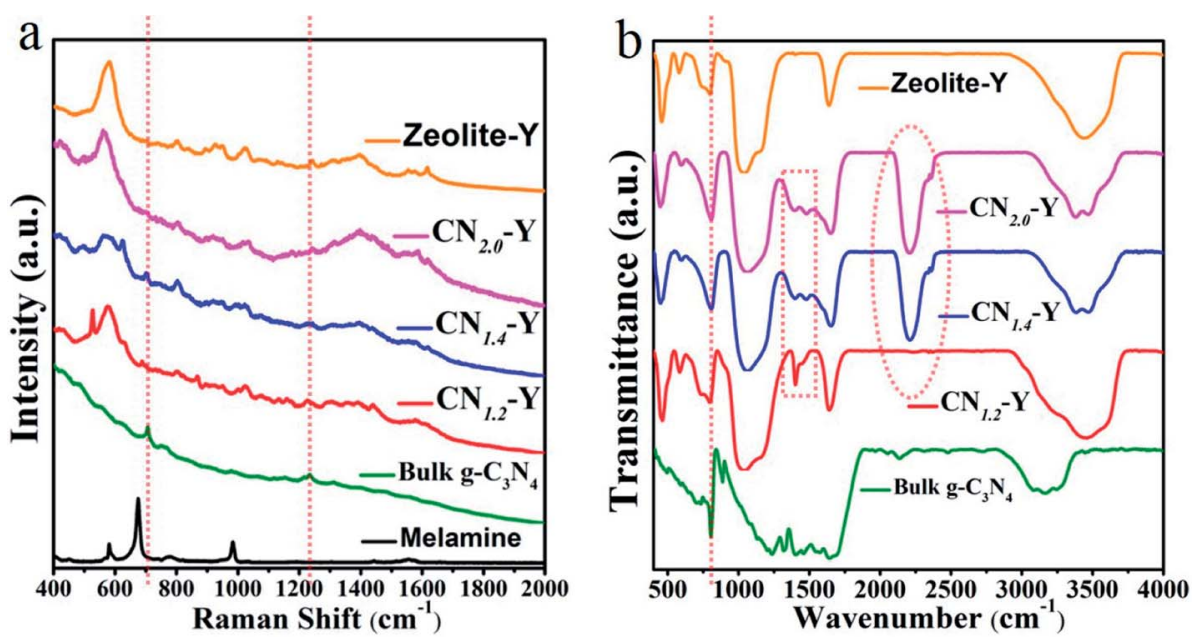

Fig. 8 (a) The Raman spectra of the $\mathrm{CN}_{r}-\mathrm{Y}(r=1.2,1.4,2.0)$, zeolite-Y, melamine and bulk g- $\mathrm{C}_{3} \mathrm{~N}_{4}$ using the near-infrared (NIR $785 \mathrm{~nm}$ ) light for excitation. (b) The FTIR spectra of the $\mathrm{CN}_{r}-\mathrm{Y}(r=1.2,1.4,2.0)$, zeolite-Y and bulk g- ${ }_{3} \mathrm{~N}_{4}$.

indicate the formation of graphite structure in bulk $\mathrm{g}$ $\mathrm{C}_{3} \mathrm{~N}_{4} \cdot{ }^{20,45,46}$ The melamine has two fingerprint peaks located at around $675 \mathrm{~cm}^{-1}$ (triazine ring breathing mode) and $1558 \mathrm{~cm}^{-1}$ ( $\mathrm{NH}_{2}$ bending mode), respectively. ${ }^{47,48}$ These two peaks disappear for the $\mathrm{CN}_{r}-\mathrm{Y}(r=1.2,1.4,2.0)$ samples, implying that the melamine has been finished after the polymerization reaction. Removing the Raman peaks of zeolite-Y, it could be seen that $\mathrm{CN}_{r}-\mathrm{Y}(r=1.2,1.4,2.0)$ samples have a tiny Raman peaks at around $707 \mathrm{~cm}^{-1}$, suggesting the existence of $\mathrm{g}^{-} \mathrm{C}_{3} \mathrm{~N}_{4}$ in the composites.

The FTIR spectra of all samples including the raw zeolite-Y, $\mathrm{CN}_{r}-\mathrm{Y}(r=1.2,1.4,2.0)$ and bulk $\mathrm{g}-\mathrm{C}_{3} \mathrm{~N}_{4}$ are shown in Fig. $8 \mathrm{~b}$. For $\mathrm{g}-\mathrm{C}_{3} \mathrm{~N}_{4}$, the peaks at around $805 \mathrm{~cm}^{-1}$ are assigned to the characteristic breathing mode of the tri-s-triazine units. ${ }^{49}$ While it superposes the peaks originated from zeolite-Y. The peaks in the $1000-1700 \mathrm{~cm}^{-1}$ region are assigned to the typical stretching modes and rotation vibration of $\mathrm{C}-\mathrm{N}$ and $\mathrm{C}=\mathrm{N}$ heterocycles in the network. ${ }^{21}$ The appearance of these peaks for $\mathrm{CN}_{r}-\mathrm{Y}(r=1.2,1.4,2.0)$ samples evidently indicate the formation of $g-\mathrm{C}_{3} \mathrm{~N}_{4}$ in the cages of zeolite-Y. Apparently, these peaks are strong for bulk $\mathrm{g}-\mathrm{C}_{3} \mathrm{~N}_{4}$. While for the $\mathrm{CN}_{r}-\mathrm{Y}$, the interaction of laser beam with $\mathrm{CN}_{r}$ is much weaker when taking the FTIR measurement since the $\mathrm{CN}_{r}$ is embedded inside the zeolite, resulting in the much weaker peaks. Moreover, there are a broad bands located in the range of $3000-3400 \mathrm{~cm}^{-1}$ region, which are assigned to the absorbed $\mathrm{H}_{2} \mathrm{O}$ molecules and uncondensed amine groups including the stretching and deformation modes of $-\mathrm{NH}_{2}$ groups. ${ }^{50-53}$

Removing the FTIR peaks of zeolite-Y, it can be seen that there is another significant peak appearing at around $2206 \mathrm{~cm}^{-1}$ for each $\mathrm{CN}_{r}-\mathrm{Y}(r=1.4$ or 2.0$)$ sample, which implies the existence of nitrile group $(\mathrm{C} \equiv \mathrm{N})$ and other similar species. And the existence of $\mathrm{C} \equiv \mathrm{N}$ in the samples is associated with drastic reactions at high temperature, resulted from the fracture of tri-s-triazine rings probably caused by the exothermic reaction of polymerization for the more concentrated melamine in $\mathrm{CN}_{r}-\mathrm{Y}(r=1.4$ or 2.0$) .^{38,54}$ The peak is absent for $\mathrm{CN}_{1.2}-\mathrm{Y}$, manifesting that few $\mathrm{C} \equiv \mathrm{N}$ is observed. It is probably due to that the exothermic reaction is not that drastic for the less concentrated melamine in the cage of the zeolite. It is also evidenced by the crystal feature of $\mathrm{CN}_{1.2}-\mathrm{Y}$ and the amorphous feature of $\mathrm{CN}_{r}-\mathrm{Y}(r=1.4$ or 2.0) in Fig. 2. Since zeolite-encapsulated particles are in a subnanoscale, ${ }^{23-26}$ it is reasonable to infer that the confining effect on condensation degree of melamine by the pores of zeolite-Y would result in a lot of $-\mathrm{NH}_{2}$ groups and $\mathrm{C} \equiv \mathrm{N}$ as defects existing in the edge of the $\mathrm{g}-\mathrm{C}_{3} \mathrm{~N}_{4}$ network. The defects cause the appearance of $\mathrm{P}_{3}$ in the PL peaks for $\mathrm{CN}_{r}-\mathrm{Y}(r$ $=1.2,1.4,2.0$ ), again proving that the $\mathrm{g}_{-} \mathrm{C}_{3} \mathrm{~N}_{4}$ are encapsulated in the pores of zeolite-Y.

\section{Conclusion}

In conclusion, we successfully synthesized the porous zeolite-Y and graphitic carbon nitride composites via a facile two-step method. Firstly, we introduce melamine into the pores of zeolite-Y via ion-exchange reaction and the resulted products are the precursors for next step. Secondly, the aimed $\mathrm{CN}_{r}-\mathrm{Y}$ products are synthesized in situ via the thermal condensation of melamine. Various characterizations, including the PL spectroscopy, evidence the formation of the $\mathrm{g}-\mathrm{C}_{3} \mathrm{~N}_{4}$ encapsulated in the pores of zeolite-Y. Owing to the confining effect of the subnanoscale cages in zeolite-Y, the $\mathrm{CN}_{r}-\mathrm{Y}$ with controlled polymerization degree of the encapsulated $\mathrm{g}^{-} \mathrm{C}_{3} \mathrm{~N}_{4}$ can be gained. The dimension of the polymeric network of the g- $\mathrm{C}_{3} \mathrm{~N}_{4}$ in the composites extends and results in red shifting of PL peak as the content of the melamine monomers is elevated. The research gives new clues to fabricate organic semiconductors with different polymerization degree in a porous zeolite, which may be intriguing in photocatalysis and optoelectronics.

\section{Conflicts of interest}

There are no conflicts to declare. 


\section{Acknowledgements}

This work is jointly supported by the NSFC (Grant No. 51772104), Local Innovative and Research Teams Project of Guangdong Pearl River Talents Program (2017Bt01X137), the Tip-top Scientific and Technical Innovative Youth Talents of Guangdong Special Support Program (2016TQ03C100), and the Guangdong Natural Science Funds for Distinguished Young Scholars (2014A030306009).

\section{References}

1 E. G. Gillan, Chem. Mater., 2000, 12, 3906-3912.

2 J. Liu, Y. Liu, N. Liu, Y. Han, X. Zhang, H. Huang, Y. Lifshitz, S. T. Lee, J. Zhong and Z. Kang, Science, 2015, 347, 970-974.

3 K. Maeda, X. Wang, Y. Nishihara, D. Lu, M. Antonietti and K. Domen, J. Phys. Chem. C, 2009, 113, 4940-4947.

4 X. Wang, K. Maeda, A. Thomas, K. Takanabe, G. Xin, J. M. Carlsson, K. Domen and M. Antonietti, Nat. Mater., 2009, 8, 76-80.

5 Y. Wang, X. Wang and M. Antonietti, Angew. Chem., 2012, 51, 68-89.

6 S. C. Yan, Z. S. Li and Z. G. Zou, Langmuir, 2010, 26, 38943901.

7 T. Xiong, H. Wang, Y. Zhou, Y. Sun, W. Cen, H. Huang, Y. Zhang and F. Dong, Nanoscale, 2018, 10, 8066-8074.

8 X. a. Dong, J. Li, Q. Xing, Y. Zhou, H. Huang and F. Dong, Appl. Catal., B, 2018, 232, 69-76.

9 P. Chen, F. Dong, M. Ran and J. Li, Chin. J. Catal., 2018, 39, 619-629.

10 X. Zou and Y. Zhang, Chem. Soc. Rev., 2015, 44, 5148-5180.

11 G. Liu, P. Niu, C. Sun, S. C. Smith, Z. Chen, G. Q. Lu and H. M. Cheng, J. Am. Chem. Soc., 2010, 132, 11642-11648.

12 Q. Xiang, J. Yu and M. Jaroniec, J. Phys. Chem. C, 2011, 115, 7355-7363.

13 S. C. Yan, Z. S. Li and Z. G. Zou, Langmuir, 2009, 25, 1039710401.

14 P. Niu, L. Zhang, G. Liu and H.-M. Cheng, Adv. Funct. Mater., 2012, 22, 4763-4770.

15 W. J. Ong, L. L. Tan, Y. H. Ng, S. T. Yong and S. P. Chai, Chem. Rev., 2016, 116, 7159-7329.

16 Y. Zheng, Y. Jiao, J. Chen, J. Liu, J. Liang, A. Du, W. Zhang, Z. Zhu, S. C. Smith, M. Jaroniec, G. Q. Lu and S. Z. Qiao, J. Am. Chem. Soc., 2011, 133, 20116-20119.

17 X. Chen, J. Zhang, X. Fu, M. Antonietti and X. Wang, J. Am. Chem. Soc., 2009, 131, 11658-11659.

18 C. Pan, J. Xu, Y. Wang, D. Li and Y. Zhu, Adv. Funct. Mater., 2012, 22, 1518-1524.

19 Y. Zhang, Q. Pan, G. Chai, M. Liang, G. Dong, Q. Zhang and J. Qiu, Sci. Rep., 2013, 3, 1943.

20 Y. Yuan, L. Zhang, J. Xing, M. I. Utama, X. Lu, K. Du, Y. Li, X. Hu, S. Wang, A. Genc, R. Dunin-Borkowski, J. Arbiol and Q. Xiong, Nanoscale, 2015, 7, 12343-12350.

21 B. Jurgens, E. Irran, J. Senker, P. Kroll, H. Muller and W. Schnick, J. Am. Chem. Soc., 2003, 125, 10288-10300.

22 J. Xu, Y. Li, S. Peng, G. Lu and S. Li, Phys. Chem. Chem. Phys., 2013, 15, 7657-7665.
23 Y. Li and J. Yu, Chem. Rev., 2014, 114, 7268-7316.

24 H. S. Kim, M. H. Lee, N. C. Jeong, S. M. Lee, B. K. Rhee and

K. B. Yoon, J. Am. Chem. Soc., 2006, 128, 15070-15071.

25 H. S. Kim, N. C. Jeong and K. B. Yoon, J. Am. Chem. Soc., 2011, 133, 1642-1645.

26 H. S. Kim, N. C. Jeong and K. B. Yoon, Langmuir, 2011, 27, 14678-14688.

27 S. Ye, J. Sun, X. Yi, Y. Wang and Q. Zhang, Sci. Rep., 2017, 7, 46219.

28 J.-Y. Sun, F. T. Rabouw, X.-F. Yang, X.-Y. Huang, X.-P. Jing, S. Ye and Q.-Y. Zhang, Adv. Funct. Mater., 2017, 27, 1704371.

29 H. Li, H. Zhang, L. Wang, D. Mu, S. Qi, X. Hu, L. Zhang and J. Yuan, Journal of Mater. Chem., 2012, 22, 9338.

30 Z. Bai, M. Fujii, K. Imakita and S. Hayashi, Microporous Mesoporous Mater., 2013, 173, 43-46.

31 K. Moller, M. M. Eddy, G. D. Stucky, N. Herron and T. Bein, ChemInform, 1989, 20, 2564-2571.

32 H. T. Sun, A. Hosokawa, Y. Miwa, F. Shimaoka, M. Fujii, M. Mizuhata, S. Hayashi and S. Deki, Adv. Mater., 2009, 21, 3694-3698.

33 A. Corma, U. Díaz, B. Ferrer, V. Fornés, M. S. Galletero and H. García, Chem. Mater., 2004, 16, 1170-1176.

34 G. A. Ozin, Adv. Mater., 1992, 4, 612-649.

35 Q. Guo, Y. Xie, X. Wang, S. Lv, T. Hou and X. Liu, Chem. Phys. Lett., 2003, 380, 84-87.

36 A. Thomas, A. Fischer, F. Goettmann, M. Antonietti, J.-O. Müller, R. Schlögl and J. M. Carlsson, Journal of Mater. Chem., 2008, 18, 4893.

37 H. A. Ma, X. P. Jia, L. X. Chen, P. W. Zhu, W. L. Guo, X. B. Guo, Y. D. Wang, S. Q. Li, G. T. Zou and G. Zhang, J. Phys.: Condens. Matter, 2002, 14, 11269.

38 J. Yang, X. Wu, X. Li, Y. Liu, M. Gao, X. Liu, L. Kong and S. Yang, Appl. Phys. A: Mater. Sci. Process., 2011, 105, 161.

39 X. Zhang, X. Xie, H. Wang, J. Zhang, B. Pan and Y. Xie, J. Am. Chem. Soc., 2013, 135, 18-21.

40 M. Groenewolt and M. Antonietti, Adv. Mater., 2005, 17, 1789-1792.

41 B. B. Wang, Q. J. Cheng, L. H. Wang, K. Zheng and K. Ostrikov, Carbon, 2012, 50, 3561-3571.

42 B. B. Wang, Q. J. Cheng, Y. A. Chen and K. Ostrikov, J. Appl. Phys., 2011, 110, 489.

43 M. Füle, J. Budai, S. Tóth, M. Veres and M. Koós, J. Non-Cryst. Solids, 2006, 352, 1340-1343.

44 X. Liu, S. Ye, G. Dong, Y. Qiao, J. Ruan, Y. Zhuang, Q. Zhang, G. Lin, D. Chen and J. Qiu, J. Phys. D: Appl. Phys., 2009, 42, 215409.

45 S. Tonda, S. Kumar, S. Kandula and V. Shanker, J. Mater. Chem. A, 2014, 2, 6772.

46 Q. Guo, Y. Zhang, H. S. Zhang, Y. Liu, Y. J. Zhao, J. Qiu and G. Dong, Adv. Funct. Mater., 2017, 27, 1703711.

47 P. V. Zinin, L. C. Ming, S. K. Sharma, V. N. Khabashesku, X. Liu, S. Hong, S. Endo and T. Acosta, Chem. Phys. Lett., 2009, 472, 69-73.

48 R. J. Meier, J. R. Maple, M. J. Hwang and A. T. Hagler, J. Phys. Chem., 1995, 99, 5445-5456.

49 J. Wei, P. Hing and Z. Q. Mo, Surf. Interface Anal., 2015, 28, 208-211. 
50 J. R. Holst and E. G. Gillan, J. Am. Chem. Soc., 2008, 130, 7373-7379.

51 M. J. Bojdys, J. O. Müller, M. Antonietti and A. Thomas, Chemistry, 2008, 14, 8177-8182.

52 S.-W. Bian, Z. Ma and W.-G. Song, J. Phys. Chem. C, 2009, 113, 8668-8672.
53 Y. Cui, J. Zhang, G. Zhang, J. Huang, P. Liu, M. Antonietti and X. Wang, Journal of Mater. Chem., 2011, 21, 13032.

54 J. Li, C. Cao, J. Hao, H. Qiu, Y. Xu and H. Zhu, Diamond Relat. Mater., 2006, 15, 1593-1600. 